\title{
Pengaruh Sudut Kemiringan Ruang Masak dan Penggunaan Lensa Fresnel terhadap Performa Kompor Surya Tipe Kotak
}

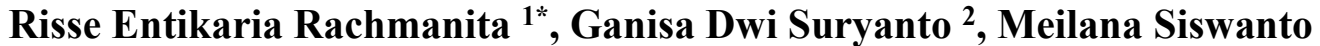 \\ ${ }^{1,2,3}$ Prodi Teknik Energi Terbarukan, Jurusan Teknik, Politeknik Negeri Jember \\ *risse_rachmanita@polije.ac.id
}

\begin{abstract}
Performance test on box solar cooker with variations in the inclination angle of the cook room and variations of the cook room cover have been carried out. The variations angle of the cook room are $10^{\circ}, 20^{\circ}$ and $30^{\circ}$ while the cook room cover uses 2 variations namely glass and a combination of fresnel glass. The size of the solar cooker is $60 \times 60$ $x 40 \mathrm{~cm}$ with a thickness of $0.9 \mathrm{~cm}$. The test was conducted in the car park behind the Engineering Building Politeknik Negeri Jember at 10:00 to 14:00 with recording every 10 minutes. The highest average solar cooker efficiency was found in solar cooker 4 with a cooking room tilt angle of $30^{\circ}$ and using a fresnel glass combination cook room cover, the efficiency is $6.7 \%$ on the first day of testing. The highest average cooking power was also found in solar cooker 4 of $24.7 \mathrm{~W}$ on the second day of testing. The highest water suhue was found in solar cooker 4 at $90^{\circ} \mathrm{C}$ on the third day of testing.
\end{abstract}

Keywords :Box Solar Cooker, hiFresnel Lens, Inclination Angle of Cook Room of Solar Cooker

\begin{abstract}
Abstrak
Pengujian performa kompor surya tipe kotak dengan variasi sudut kemiringan ruang masak dan variasi penutup ruang masak telah dilakukan. Variasi sudut kemiringan ruang masak menggunakan sudut $10^{\circ}, 20^{\circ}$ dan $30^{\circ}$ sedangkan penutup ruang masak menggunakan 2 variasi yaitu kaca dan kombinasi kaca fresnel. Ukuran kompor surya adalah 60 x 60 x $40 \mathrm{~cm}$ dengan ketebalan $0,9 \mathrm{~cm}$. Pengujian dilakukan di parkiran mobil belakang Gedung Teknik Politeknik Negeri Jember pada jam 10.00 sampai 14.00 dengan pencatatan setiap 10 menit sekali. Rata-rata effisiensi kompor surya tertinggi terdapat pada kompor surya 4 dengan sudut kemiringan ruang masak $30^{\circ}$ dan menggunakan penutup ruang masak kombinasi kaca fresnel sebesar $6,7 \%$ pada pengujian hari pertama. Rata-rata daya masak tertinggi juga terdapat pada kompor surya 4 sebesar $24,7 \mathrm{~W}$ pada pengujian hari kedua. Suhu air tertinggi terdapat pada kompor surya 4 sebesar $90^{\circ} \mathrm{C}$ pada pengujian hari ketiga.
\end{abstract}

Kata kunci :Kompor Surya Tipe Kotak, Lensa Fresnel, Sudut Kemiringan Ruang Masak Kompor Surya

\section{Pendahuluan}

Indonesia memiliki potensi energi surya yang cukup besar sepanjang tahunnya, karena hanya memiliki 2 musim dan berada dalam wilayah khatulistiwa. Penggunaan energi surya di Indonesia merupakan alternatif yang tepat untuk kebutuhan industri maupun rumah tangga.Kebutuhan rumah tangga yang utama dalam kehidupan sehari-hari adalah untuk keperluan memasak. Pemanfaatan energi matahari sebagai sumber energi terbarukan sangatlah penting dalam mencegah semakin berkurangnya energi fosil yang ada di bumi. Bahan bakar minyak yang sering kita gunakan dalam kebutuhan sehari-hari semakin lama akan semakin habis ketersediannya [1]. Kayu 
bakar yang tergeser oleh minyak tanah dan elpiji mulai diminati kembali akan tetapi potensi kayu bakar juga tidak dapat diprediksi saat musim penghujan dan pembangunan infrastruktur yang sangat pesat juga bisa mempengaruhi ketersediaan kayu bakar itu sendiri [2]. Pemanfaatan energi matahari untuk memasak salah satunya dapat dikembangkan dengan pembuatan kompor tenaga surya.

Tipe kompor surya pada umumnya menggunakan tipe parabola dan tipe kotak. Kompor surya tipe kotak lebih sering dikembangkan karena pengoperasiannya yang sederhana. Menurut Organisasi Kesehatan Dunia (WHO), kompor surya memiliki kelebihan diantaranya adalah tidak menimbulkan polusi, tidak berdampak buruk bagi lingkungan di sekitarnya dan hemat biaya. Prinsip kerja kompor surya pada umumnya memanfaatkan cahaya matahari yang difokuskan pada suatu titik [3], [4]. Sehingga dapat menghasilkan efektifitas yang tinggi, hemat, aman, dan ramah lingkungan dibandingkan kompor tungku dan kompor gas elpiji. Cara kerja perpindahan panas dari kompor surya ada beberapa mekanisme. Pertama, radiasi langsung (direct solar rays) yaitu sinar matahari difokuskan ke titik obyek yang akan dimasak. Kedua, melalui konveksi yaitu sinar matahari masuk kedalam kolektor dan membuat suhu di dalamnya menjadi panas. Obyek mendapatkan efisiensi panas dari suhu ruangan di dalam kolektor [4], [5].

Ketiga, melalui proses konduksi yaitu perpindahan panas akibat sinar matahari yang diserap oleh kolektor plat logam (baja atau aluminium). Obyek yang digunakan diletakkan di atas plat logam kemudian panas dari plat logam akan dihantarkan ke obyek tersebut [6], [7]. Gabungan dari ketiga kombinasi mekanisme perpindahan panas ini akan meningkatkan efisiensi proses memasak dari kompor surya.

Salah satu tantangan utama untuk meningkatkan efisiensi kompor surya adalah kemampuan mentransfer dan memusatkan sinar matahari ke kolektor [8], [9]. Tipe concentrating cooker mempunyai beberapa kelebihan yaitu efisiensi tinggi, suhu yang cukup tinggi (bisa digunakan proses penggorengan) dan memasakpun akan lebih cepat [10], [11]. Oleh karena itu, peneliti ingin menerapkan proses perpindahan panas melalui tahap radiasi, konveksi, konduksi dengan variasi sudut kemiringan ruang masak dan penutup kolektor. Penutup kolektor yang akan divariasikan dalam penelitian ini menggunakan kaca dan kombinasi kaca fresnel. Penggunaan lensa fresnel pada kompor surya untuk memfokuskan panas dan mempercepat waktu untuk memanaskan air hingga mendidih. Perbaikan kompor untuk meningkatkan efisiensi transfer panas dengan memberikan serat alumunium untuk menjaga panas didalam kompor dan sudut kemiringan yang akan digunakan adalah sudut $10^{\circ}, 20^{\circ}$, dan $30^{\circ}$. Dalam hal ini objek yang akan di uji menggunakan air sebanyak 1 liter.

\section{Metoda Penelitian}

\subsection{PerancanganDesain Kompor Surya}

Dalam perancangan spesifikasi desain yang digunakan untuk penelitian ini sebagai berikut:

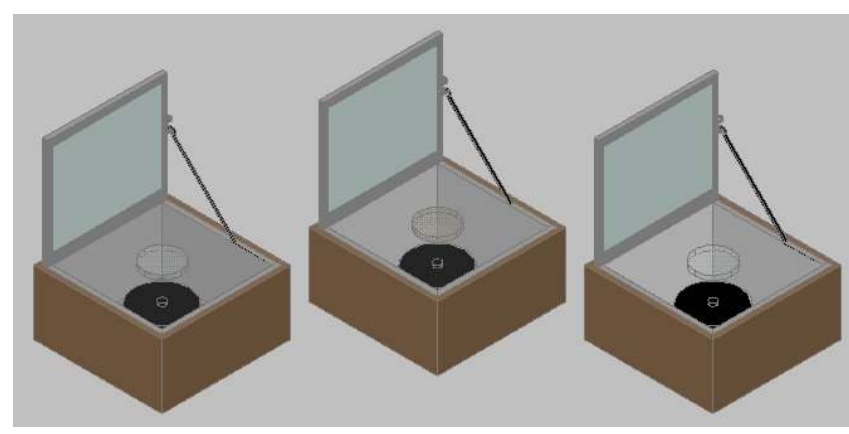

Gambar 1. Desain Kompor Surya Tipe Kotak

Kompor surya tipe kotak yang akan digunakan dalam penelitian ini memiliki ukuran panjang 60, lebar $60 \mathrm{~cm}$ dan tinggi 40 $\mathrm{cm}$. Bahan utama kompor menggunakan kayu triplek. Dalam penelitian ini menggunakan satu reflektor dengan bahan cermin agar dapat memantulkan cahaya matahari sehingga dapat masuk ke absorber. Pada bagian absorber setiap sisi dilapisi dengan aluminium foil agar panas dapat terperangkap di dalam ruang 
masak. Isolator yang digunakan pada rongga sudut menggunakan styrofoam agar panas tidak keluar ke bagian luar kompor.

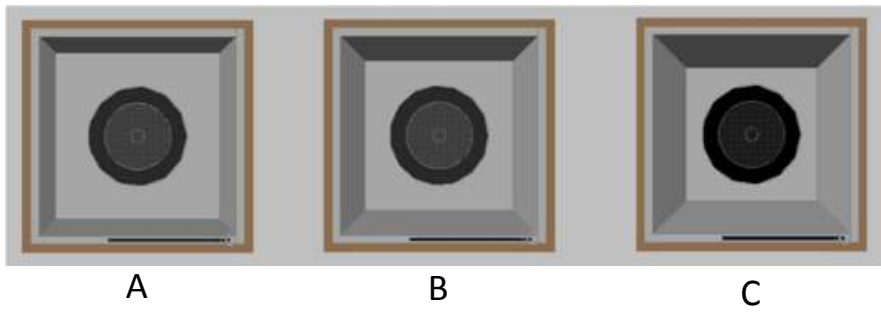

Gambar 2. Ruang Masak Kompor Surya

Variasi kemiringan sudut yang akan di gunakan dalam penelitian ini adalah $10^{\circ}, 20^{\circ}$ dan $30^{\circ}$. Gambar A dengan kemiringan sudut $10^{\circ}$, gambar $\mathrm{B}$ kemiringan sudut $20^{\circ}$ dan gambar $\mathrm{C}$ kemiringan sudut $30^{\circ}$. Semakin besar sudut kemiringan ruang masak maka luas alas ruang masak akan semakin kecil.

Variasi penutup absorber yang digunakan dalam penelitian ini ada 2, yaitu menggunakan penutup kolektor kombinasi kaca dan lensa fresnel, lensa fresnel yang digunakan memiliki ukuran $30 \times 30 \mathrm{~cm}$ dan dengan penutup kolektor menggunakan kaca dengan dimensi mengikuti luas kompor.

\subsection{Uji Kinerja Kompor Surya}

Uji kinerja kompor surya bertujuan untuk mengetahui bagaimana pengaruh perubahan suhu air tertinggi pada efisiensi kompor surya. Metode yang digunakan dalam pengujian ini adalah metode Water Boiling Test (WBT). WBT adalah metode yang menyimulasikan secara kasar dari proses pemasakan, untuk mengetahui seberapa baik energi panas dapat ditransfer pada alat masak [3], [12]. Pengujian kompor surya dengan metode WBT dilakukan pada pukul 10.00 sampai 14.00 WIB, waktu tersebut mempunyai intensitas matahari sangat tinggi ketika cuaca cerah. Dalam pengujian menggunakan WBT, menggunakan volume air sebanyak 1 liter.

Parameter yang diukur dalam penelitian kompor surya tipe kotak dengan variasi sudut kemiringan ruang masak adalah sebagai berikut : a. Perhitungan Luas Permukaan Kompor

Luas permukaan adalah total keseluruhan permukaan suatu benda, yang dihitung dengan menjumlahkan seluruh permukaan pada benda tersebut. Rumus luas permukaan kompor adalah:

L.Permukaan $=$ L. Alas + L. Trapesium $1+$ L. Trapesium $2+$ L. Trapesium $3+$ L. Trapesium 4

b. Estimasi Daya Masak

Pengujian kompor surya memiliki standart yang mengacu pada ASAE 2003 (American Society Of Agricultural Engineers) menetapkan bahwa hasil dari estimasi daya masak akan disajikan dalam satuan Watt. Dan hasil dari perhitungan estimasi daya masak sendiri akan di normalisasikan dengan estimasi daya masak tiap interval waktu pangambilan data[11].

c. Record

Mencatat suhu air, suhu panci, dan suhu absorber pada kompor surya yang diuji dengan interval waktu 10 menit dalam satuan ${ }^{\circ} \mathrm{C}$, radiasi matahari dalam satuan $\mathrm{W} / \mathrm{m}^{2}$, Kecepatan angin dalam satuan $\mathrm{m} / \mathrm{s}$, suhu lingkungan dalam satuan ${ }^{\circ} \mathrm{C}$.

d. Menghitung Daya Masak

Waktu pengujian menggunakan interval 10 menit atau selama 600 detik. Sehingga untuk mengetahui daya masak kompor maka perubahan suhu air dikalikan dengan massa air dan panas jenis air yang hasilkan dibagi selang waktu pengukuran yaitu 600 detik. Rumus daya masak adalah[10]:

$\mathrm{P}_{\mathrm{i}}=\frac{(T 2-T 1) m \cdot C}{t}$.

Dimana :

$\mathrm{P}_{\mathrm{i}}=$ Daya Masak $(\mathrm{W})$;

$\mathrm{T}_{2}=$ Suhu Air Akhir $\left({ }^{\circ} \mathrm{C}\right)$;

$\mathrm{T}_{1}=$ Suhu Air Awal $\left({ }^{\circ} \mathrm{C}\right)$;

$\mathrm{m}=$ Massa Air $(\mathrm{Kg})$;

$\mathrm{C}=$ Panas Jenis air $\left(4186 \mathrm{~J} / \mathrm{Kg}{ }^{\circ} \mathrm{C}\right)$;

$\mathrm{T}=$ Interval waktu (s).

e. Perhitungan Efisiensi Termal Kompor Surya

Efisiensi kompor surya diperoleh dari hasil perhitungan yang diterima oleh air dibagi 
dengan waktu pertambahan energi, sehingga diperoleh daya dalam satuan watt dan dibagi dengan daya yang diterima kompor dikali $100 \%$ [2]

$(\eta)=\frac{Q_{\text {out }}}{Q_{\text {in }}} \times 100 \%$

Dimana:

$\mathrm{Q}_{\text {in }}=$ Daya yang diterima kompor $(\mathrm{W})$;

$\mathrm{Q}_{\text {out }}=$ Energi yang diterima air $(\mathrm{J})$.

Energi yang diterima kompor dapat ditentukan dengan mengkalikan luas permukaan ruang masak pada kompor dengan intensitas radiasi [2]:

$\mathrm{Q}_{\text {in }}=\mathrm{A}_{\mathrm{c}}$. Total Ir

Dimana:

$\mathrm{Q}_{\text {in }}=$ Daya yang diterima kompor $(\mathrm{W})$;

$\mathrm{A}_{\mathrm{c}}=$ Luas permukaan kompor $\left(\mathrm{m}^{2}\right)$;

$\mathrm{I}_{\mathrm{r}}=$ Intensitas radiasi matahari $\left(\mathrm{W} / \mathrm{m}^{2}\right)$.

Qout merupakan energi yang diterima

oleh air sehingga energi tersebut digunakan acuan untuk memperoleh hasil efisiensi kompor, Qout dapat diperoleh menggunakan rumus sebagai berikut:

$\mathrm{Q}_{\text {out }}=\mathrm{m} \cdot \mathrm{C}\left(\mathrm{T}_{2}-\mathrm{T}_{1}\right)$

Dimana:

$\mathrm{Q}_{\text {out }}=$ Energi yang diterima air $(\mathrm{J})$;

$\mathrm{M}$ = Masa air $(\mathrm{Kg})$;

$\mathrm{Cp}=$ Panas Jenis air $\left(4186 \mathrm{~J} / \mathrm{kg}^{\circ} \mathrm{C}\right)$;

$\mathrm{T}_{2}=$ Suhu akhir air $\left({ }^{\circ} \mathrm{C}\right)$;

$\mathrm{T}_{1}=$ Suhu awal air $\left({ }^{\circ} \mathrm{C}\right)$.

\section{Hasil Penelitian}

\subsection{Rancang Bangun Kompor Surya Tipe} Kotak

Hasil rancangan kompor surya tipe kotak dengan variasi sudut $10^{\circ}, 20^{\circ}, 30^{\circ}$ yang sudah dibuat dapat dilihat pada Gambar 3 yaitu menggunakan 6 buah kompor surya dengan variasi penutup absorber lensa fresnel dan kaca dan setiap kompor masing-masing menggunakan 1 buah reflektor cermin tebal 2 $\mathrm{mm}$, kotak kompor surya terbuat dari triplek dengan tebal $9 \mathrm{~mm}$, isolator terbuat dari styrofoam, absorber dilapisi aluminium foil dan penutup absorber menggunakan kaca dengan tebal $5 \mathrm{~mm}$. Kompor 1 dengan sudut $30^{\circ}$ dengan penutup kaca, kompor 2 sudut $20^{\circ}$ penutup kaca, kompor 3 sudut $10^{\circ}$ penutup kaca, kompor 4 sudut $30^{\circ}$ penutup kaca kombinasi fresnel, kompor 5 sudut $20^{\circ}$ penutup kaca kombinasi fresnel, kompor 6 sudut $10^{\circ}$ penutup kaca kombinasi fresnel.

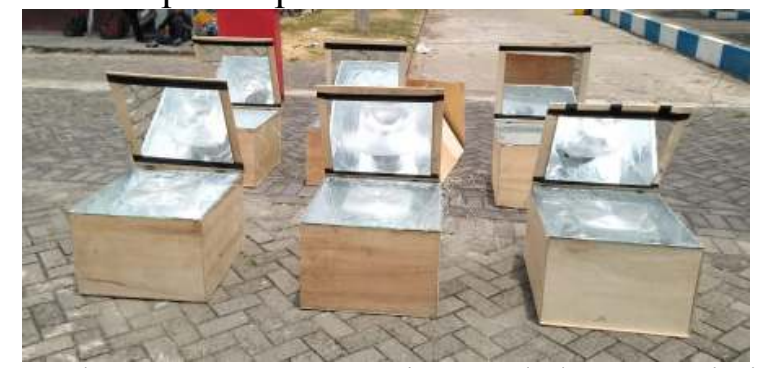

Gambar 3. Kompor Surya Tipe Kotak dengan Variasi Sudut Ruang Masak

Kayu triplek digunakan sebagai rangka dan penyangga kompor surya yang bereflektor cermin agar kuat menopang beban cermin yang relatif lebih berat. Masing - masing kompor dilengkapi dengan kaca dan isolator, yang dalam pengujian ini penggunaan kaca diharapkan bisa mengurangi kehilangan panas terhadap lingkungan, dan penggunaan styrofoam diharapkan dapat mengurangi kehilangan panas yang keluar dari ruang masak yang terbuat dari alumunium foil.

Dalam pengaplikasian ini, kompor surya dengan penambahan reflektor tidak mengikuti arah pantulan sinar matahari melainkan reflektor tetap menghadap ke arah utara karena apabila mengikuti arah matahari sensor yang sudah terpasang akan rawan lepas akibat sering di geser.

Tabel 1 Spesifikasi Kompor Surya Hasil Rancangan

\begin{tabular}{|c|c|c|c|c|}
\hline Parameter & Bahan & $\begin{array}{c}\text { Panjang } \\
(\mathrm{cm})\end{array}$ & $\begin{array}{l}\text { Lebar } \\
(\mathrm{cm})\end{array}$ & $\begin{array}{l}\text { Tebal } \\
(\mathrm{mm})\end{array}$ \\
\hline \multirow{2}{*}{ Reflektor } & Cermin & 50 & 50 & 2 \\
\hline & Triplek & 60 & 60 & 9 \\
\hline \multirow{2}{*}{$\begin{array}{l}\text { Selubung } \\
\text { kompor }\end{array}$} & $\begin{array}{c}\text { Lensa } \\
\text { Fresnel }\end{array}$ & 30 & 30 & 10 \\
\hline & Triplek & 60 & 60 & 9 \\
\hline \multirow{2}{*}{$\begin{array}{c}\text { Insulation } \\
\text { Ruang } \\
\text { Masak }\end{array}$} & Styrofoam & 58 & 58 & 75 \\
\hline & $\begin{array}{l}\text { Alumunium } \\
\text { foil }\end{array}$ & 60 & 60 & 0,5 \\
\hline
\end{tabular}

\subsection{Pengujian Pengaruh Sudut Kemiringan Ruang Masak terhadap Performa Kompor Surya Tipe Kotak dengan Penutup Kaca}

Hasil pengujian kompor surya dengan penutup kaca dan variasi sudut ruang masak 
didapatkan suhu tertinggi air pemasakan pada pengujian hari ke-2 yaitu $83{ }^{\circ} \mathrm{C}$ pada Kompor Surya 1 dengan sudut kemiringan ruang masak $30^{\circ}$.

Sebagai parameter uji performa kompor surya, Gambar 4 dan Gambar 5 menunjukkan kondisi intensitas radiasi matahari dan kecepatan angin pada hari tersebut.

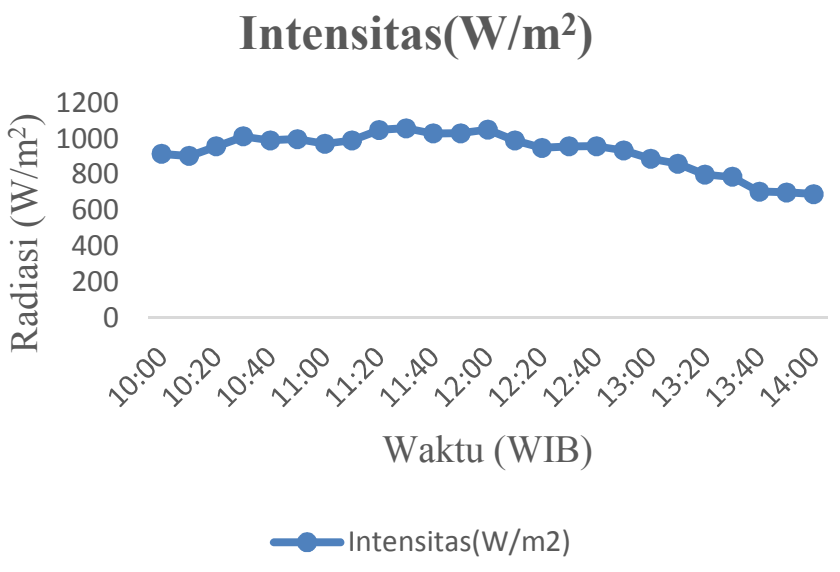

Gambar 4. Intensitas Radiasi Matahari pada Pengujian Hari Kedua

Intensitas radiasi matahari merupakan besaran daya per satuan luas. Intensitas radiasi matahari pada setiap harinya tidak memiliki kestabilan sehingga mempengaruhi suhu lingkungan yang dihasilkan. Intensitas radiasi tertinggi terjadi pada pukul 11.30 sebesar $1060 \mathrm{~W} / \mathrm{m}^{2}$ dan intensitas radiasi matahari terendah terletak pada pukul 14.00 sebesar 692 $\mathrm{W} / \mathrm{m}^{2}$ sedangkan pengujian awal intensitas radiasi matahari sebesar $916 \mathrm{~W} / \mathrm{m}^{2}$. Rata-rata intensitas radiasi matahari pada pengujian hari kedua adalah 928,4 W/m². Perbedaan intensitas radiasi matahari dalam proses pengukuran mempengaruhi kenaikan suhu dalam kompor.

\section{Kecepatan Angin(m/s)}



Gambar 5. Kecepatan Angin pada Pengujian Hari Kedua

Kecepatan angin tertinggi pada hari kedua terjadi pada pukul 13.20 sebesar 10,3 $\mathrm{m} / \mathrm{s}$ dan kecepatan angin terendah terjadi pada pukul 10.10 yaitu $0,2 \mathrm{~m} / \mathrm{s}$. Semakin kecil angin yang terdapat pada tempat pengujian maka semakin kecil kehilangan panas yang terdapat pada ruang pemasakan.

Sedangkan hasil pengujian kompor surya 1, 2 dan 3 ditunjukkan pada Gambar 6. Suhu lingkungan pada setiap harinya tidak memiliki kestabilan karena cuaca sering berubah-ubah sehingga mempengaruhi daya masak yang dihasilkan kompor surya. Suhu lingkungan tertinggi pada pengujian hari kedua terjadi pada pukul 10.50 sebesar $34,7{ }^{\circ} \mathrm{C}$ dan suhu terendah terletak pada pukul 10.00 sebesar $31,1^{\circ} \mathrm{C}$.

$$
\begin{array}{lr} 
& 100 \\
\text { 늘 } & 50 \\
\text { 돌 } & 0
\end{array}
$$

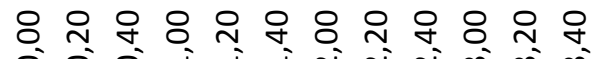
苂

Waktu (WIB)

$\longrightarrow$ Suhu Air Kompor Surya 1

$\longrightarrow$ Suhu Air Kompor Surya 2

- Suhu Air Kompor Surya 3

—Suhu Lingkungan

Gambar 6.Perbandingan Suhu Air Kompor Surya 1, 2 dan 3 pada Pengujian Hari Kedua 
Pada pengujian hari kedua kompor surya 1 dengan sudut $30^{\circ}$ dengan penutup ruang masak kaca mampu menaikkan suhu air hingga $83^{\circ} \mathrm{C}$ pada jam 12.20 dan intensitas radiasi matahari yang diterima kompor surya yaitu $950 \mathrm{~W} / \mathrm{m}^{2}$, pada saat suhu lingkungan mencapai $32,7^{\circ} \mathrm{C}$ dan kecepatan angin $3,6 \mathrm{~m} / \mathrm{s}$. Kompor surya 2 dengan sudut $20^{\circ}$ dengan penutup ruang masak kaca mampu menaikkan suhu air hingga $82^{\circ} \mathrm{C}$ pada jam 12.20 sedangkan kompor surya 3 dengan sudut $10^{\circ}$ dengan penutup ruang masak kaca mampu menaikkan suhu air hingga $69^{\circ} \mathrm{C}$ pada jam 13.30 dan energi radiasi matahari yang diterima kompor surya yaitu $788 \mathrm{~W} / \mathrm{m}^{2}$, pada saat suhu lingkungan mencapai $33,5^{\circ} \mathrm{C}$ dan kecepatan angin $0,6 \mathrm{~m} / \mathrm{s}$.

Selama proses pemasakan air pada kompor surya 1, 2 dan 3 di hari kedua yang memanfaatkan energi matahari untuk memanaskan air sebanyak 1 liter didapatkan nilai tertinggi dan rata-rata daya masak kompor surya 1 sebesar 26,9 W dan 19,5 W dengan nilai efisiensi termal tertinggi dan ratarata sebesar 5,8\% dan 4\%. Pada kompor surya 2 didapatkan nilai tertinggi dan rata-rata daya masak sebesar 23,5 W dan 17,1 W dengan nilai efisiensi termal tertinggi dan rata-rata sebesar 3,9\% dan 3\%. Pada kompor surya 3 didapatkan nilai tertinggi dan rata-rata daya masak sebesar $18 \mathrm{~W}$ dan 13,5 $\mathrm{W}$ dengan nilai efisiensi termal tertinggi dan rata-rata sebesar $2,7 \%$ dan $2,1 \%$.

\subsection{Pengujian Pengaruh Pengaruh Sudut Kemiringan Ruang Masak terhadap Performa Kompor Surya Tipe Kotak dengan Penutup Kaca dan Lensa Fresnel}

Hasil pengujian pengaruh sudut kemiringan ruang masak terhadap performa kompor surya tipe kotak dengan penutup kombinasi kaca dan lensa fresnel dapat dilihat pada Gambar 7. Pada pengujian hari kedua kompor surya 4 dengan sudut $30^{\circ}$ dan penutup ruang masak kaca dan fresnel mampu menaikkan suhu air hingga $86^{\circ} \mathrm{C}$ pada jam
12.20 dan energi radiasi matahari yang diterima kompor surya yaitu $950 \mathrm{~W} / \mathrm{m}^{2}$, pada saat suhu lingkungan mencapai $32,7^{\circ} \mathrm{C}$ dan kecepatan angin 3,6 m/s. Selama proses pemasakan kompor surya yang memanfaatkan energi matahari untuk memanaskan air sebanyak 1 liter didapatkan nilai daya masak tertinggi dan rata-rata sebesar $30,4 \mathrm{~W}$ dan 21,1 $\mathrm{W}$ dan nilai efisiensi termal tertinggi dan ratarata sebesar $6 \%$ dan $4,3 \%$.

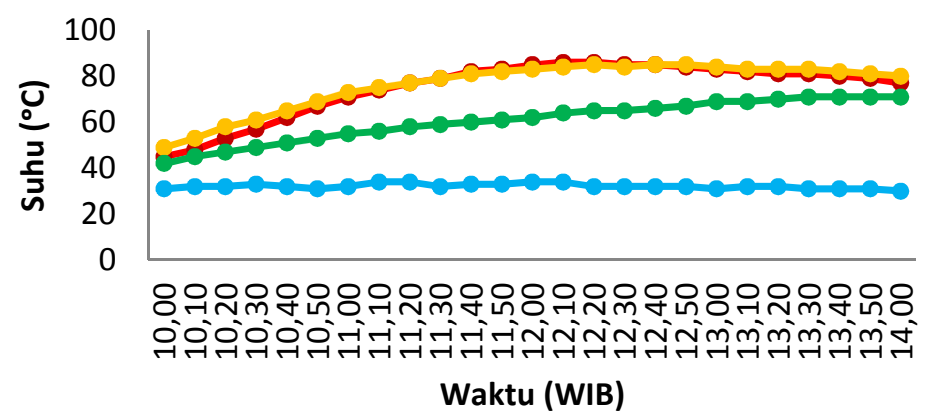

$\longrightarrow$ Suhu Air Kompor Surya $4 \longrightarrow$ Suhu Air Kompor Surya 5
$\longrightarrow$ Suhu Air Kompor Surya $6 \longrightarrow$ Suhu Lingkungan

Gambar 7. Perbandingan Suhu Air Kompor Surya 4, 5 da 6 pada Pengujian Hari Kedua

Kompor surya 5 dengan sudut $20^{\circ}$ dan penutup ruang masak kaca dan fresnel mampu menaikkan suhu air hingga $85^{\circ} \mathrm{C}$ pada jam 12.20 dan energi radiasi matahari yang diterima kompor surya yaitu $950 \mathrm{~W} / \mathrm{m}^{2}$, pada saat suhu lingkungan mencapai $32,7^{\circ} \mathrm{C}$ dan kecepatan angin 3,6 m/s. Selama proses pemasakan air didapatkan nilai daya masak tertinggi dan rata-rata sebesar 29,5 W dan 19,2 $\mathrm{W}$ dan nilai efisiensi termal tertinggi dan ratarata sebesar 3,3\%.

Kompor surya 6 dengan sudut $10^{\circ}$ dan penutup ruang masak kaca dan fresnel mampu menaikkan suhu air hingga $71^{\circ} \mathrm{C}$ pada jam 13.30 dan energi radiasi matahari yang diterima kompor surya yaitu $788 \mathrm{~W} / \mathrm{m}^{2}$, pada saat suhu lingkungan mencapai $33,5^{\circ} \mathrm{C}$ dan kecepatan angin $0,6 \mathrm{~m} / \mathrm{s}$. Selama proses pemasakan air 1 liter didapatkan nilai daya masak tertinggi dan rata-rata sebesar $15,7 \mathrm{~W}$ dan 11,8 $\mathrm{W}$ dan nilai efisiensi termal tertinggi dan rata-rata sebesar $2,5 \%$ dan $1,8 \%$. 


\subsection{Perbandingan Uji Performa Kompor Surya Tipe Kotak dengan Variasi Sudut Kemiringan dan Penutup Ruang Masak}

Hasil dari pengujian yang telah selesai dilakukan menunjukkan adanya perubahan suhu air, panci dan lingkungan, perubahan suhu tersebut sangat dipengaruhi oleh intesitas radiasi matahari dan suhu lingkungan. Pengulangan pada pengujian dilakukan bertujuan diharapkan mampu memberikan variasi data sehingga dapat membandingkan efisiensi dari masing-masing kompor surya.

Tabel 2. Data Studi Kompor Surya Tipe Kotak Pengujian Hari Pertama

\begin{tabular}{|c|c|c|c|c|c|c|c|}
\hline \multirow{2}{*}{ No } & \multirow{2}{*}{ Parameter } & \multicolumn{6}{|c|}{ Kompor Surya } \\
\hline & & 1 & 2 & 3 & 4 & 5 & 6 \\
\hline 1 & $\begin{array}{l}\text { Tair maks } \\
\left({ }^{\circ} \mathrm{C}\right)\end{array}$ & 83 & 82 & 69 & 86 & 85 & 71 \\
\hline & Waktu & 12.2 & 12.2 & 13.3 & 12.2 & 12.2 & 13.30 \\
\hline 2. & $\begin{array}{l}\mathrm{T}_{\text {air maks }} \\
\text { (WIB) }\end{array}$ & 0 & 0 & 0 & 0 & 0 & 13.30 \\
\hline 3 & $\begin{array}{l}\text { Durasi } T_{\text {air }} \\
\text { maks }(\text { Menit } \\
\text { ) }\end{array}$ & 140 & 140 & 220 & 140 & 140 & 220 \\
\hline 4 & $\begin{array}{l}\eta_{\text {tertinggi }} \\
(\%)\end{array}$ & 10,3 & 8,3 & 5,0 & 15,0 & 10,9 & 8,5 \\
\hline 5 & $\begin{array}{l}\eta_{\text {rata-rata }} \\
(\%)\end{array}$ & 3,6 & 2,6 & 1,6 & 3,8 & 2,8 & 1,6 \\
\hline 6 & $\begin{array}{l}\text { PTertinggi( } \\
\text { W) }\end{array}$ & 29,7 & 26,8 & 23,5 & 39,7 & 40,1 & 41,4 \\
\hline 7 & $\begin{array}{l}\mathrm{P} \text { Rata- } \\
\text { rata }(\mathrm{W})\end{array}$ & 17,9 & 15,6 & 9,1 & 18,8 & 16,5 & 9,1 \\
\hline
\end{tabular}

Rata-rata daya masak dan efisiensi kompor surya pada pengujian hari pertama yang tertinggi di dapat oleh kompor 4 dengan sudut $30^{\circ}$ dan penutup absorber kombinasi kaca fresnel. Hal ini karena semakin sempit ruang pemasakan kompor surya akan semakin kecil pula mengalami kehilangan panas atau losses. Besarnya daya masak dan efisiensi pada kompor 4 juga di pengaruhi oleh penutup absorber dengan menggunakan lensa fresnel yang langsung memfokuskan cahaya ke panci.

Berdasarkan data pengujian yang telah dilakukan nilai suhu air maksimal yang dihasilkan setiap kompor berbeda-beda tergantung luas permukaan kompor, penutup absorber, kondisi cuaca, intensitas radiasi matahari dan kecepatan anginnya.
Pada Tabel 2. kompor surya 4 memiliki nilai suhu air paling besar dibandingkan dengan yang lain. Hal ini disebabkan karena luas permukaan kompor surya 4 yang tidak terlalu besar sehingga panas akan terperangkap secara maksimal ke panci dan dengan adanya penambahan penutup absorber lensa fresnel membuat titik fokus cahaya lebih terfokus ke panci. Dengan adanya penambahan penutup kolektor lensa fresnel pada kompor 4, 5 dan 6 juga mempercepat peningkatan suhu air dibandingkan dengan penutup kaca biasa yang di pakai pada kompor 1, 2 dan 3. Dapat diperbandingkan pada kompor 1 dan 4, pada waktu yang sama kompor 1 suhu air maksimalnya $73^{\circ} \mathrm{C}$ sedangkan pada kompor 4 sudah mencapai suhu air $86^{\circ} \mathrm{C}$ dan efísiensi yang dihasilkam pun terlihar pada kompor 4 yang memiliki efisiensi daya masak cukup baik sebesar $3,7 \%$ dan daya masak sebesar $21,2 \mathrm{~W}$.

Tabel 3. Data Studi Kompor Surya Tipe Kotak Pengujian Hari Kedua

\begin{tabular}{|c|c|c|c|c|c|c|c|}
\hline \multirow{2}{*}{ No } & \multirow{2}{*}{ Parameter } & \multicolumn{6}{|c|}{ Kompor Surya } \\
\hline & & 1 & 2 & 3 & 4 & 5 & 6 \\
\hline 1 & $\begin{array}{l}\text { Tair maks } \\
\left({ }^{\circ} \mathrm{C}\right)\end{array}$ & 83 & 82 & 69 & 86 & 85 & 71 \\
\hline & Waktu & 12.2 & 12.2 & 13.3 & 12.2 & 12.2 & 13.30 \\
\hline 2. & $\begin{array}{l}T_{\text {air maks }} \\
\text { (WIB) }\end{array}$ & 0 & 0 & 0 & 0 & 0 & \\
\hline 3 & $\begin{array}{l}\text { Durasi Tair } \\
\text { maks(Menit } \\
\text { ) }\end{array}$ & 140 & 140 & 220 & 140 & 140 & 220 \\
\hline 4 & $\begin{array}{l}\eta_{\text {tertinggi }} \\
(\%)\end{array}$ & 5,8 & 3,9 & 2,7 & 6,0 & 4,7 & 2,5 \\
\hline 5 & $\begin{array}{l}\eta_{\text {rata-rata }} \\
(\%)\end{array}$ & 3,6 & 2,6 & 1,6 & 3,8 & 2,8 & 1,6 \\
\hline 6 & $\begin{array}{l}\text { PTertinggi( } \\
\text { W) }\end{array}$ & 27,5 & 23,3 & 18,0 & 30,4 & 29,5 & 15,7 \\
\hline 7 & $\begin{array}{l}P_{\text {Rata- }} \\
\text { rata( }(W)\end{array}$ & 17,9 & 15,6 & 9,1 & 18,8 & 16,5 & 9,1 \\
\hline
\end{tabular}

Rata-rata daya masak dan efisiensi kompor surya pada pengujian hari kedua yang tertinggi tetap di dapat oleh kompor 4 dengan sudut $30^{\circ}$ dan penutup absorber kombinasi kaca fresnel. Hal ini karena semakin sempit ruang pemasakan kompor surya akan semakin kecil pula mengalami kehilangan panas atau losses. Besarnya daya masak dan efisiensi pada kompor 4 juga di pengaruhi oleh penutup 
absorber dengan menggunakan lensa fresnel yang langsung memfokuskan cahaya ke panci.

Pada Tabel 3. kompor surya 4 tetap memiliki nilai suhu air dan efisiensi daya masak yang paling besar dibandingkan dengan yang lain. Akan tetapi pada pengujian hari kedua radiasi matahari yang dihasilkan lebih besar daripada hari pertama dengan rata-rata radiasi 928,4 sedangkan radiasi di hari pertama rata-rata sebesar 714,2. Radiasi di hari kedua cukup stabil bila dibandingkan hari pertama, hal ini mempengaruhi suhu air yang dihasilkan pada masing-masing kompor. Akan tetapi pada kompor 3 dan 6 kenaikan suhu air cukup lambat yaitu pada menit 220 .

Tabel 4. Data Studi Kompor Surya Tipe Kotak Pengujian Hari Ketiga

\begin{tabular}{|c|c|c|c|c|c|c|c|}
\hline \multirow{2}{*}{ No } & \multirow{2}{*}{ Parameter } & \multicolumn{6}{|c|}{ Kompor Surya } \\
\hline & & 1 & 2 & 3 & 4 & 5 & 6 \\
\hline \multirow[t]{2}{*}{1} & $\begin{array}{l}\mathrm{T}_{\text {air maks }} \\
\left({ }^{\circ} \mathrm{C}\right)\end{array}$ & 81 & 80 & 71 & 90 & 83 & 78 \\
\hline & Waktu & 12.4 & 12.4 & 12.5 & 12.4 & 12.4 & 12.40 \\
\hline 2. & $\begin{array}{l}\mathrm{T}_{\text {air maks }} \\
\text { (WIB) }\end{array}$ & 0 & 0 & 0 & 0 & 0 & \\
\hline 3 & $\begin{array}{l}\text { Durasi } T_{\text {air }} \\
\text { maks }(\text { Menit } \\
\text { ) }\end{array}$ & 170 & 170 & 180 & 170 & 170 & 170 \\
\hline 4 & $\begin{array}{l}\eta_{\text {tertinggi }} \\
(\%)\end{array}$ & 8,0 & 6,6 & 3,6 & 9,3 & 7,5 & 5,3 \\
\hline 5 & $\begin{array}{l}\eta_{\text {rata-rata }} \\
(\%)\end{array}$ & 3,2 & 2,5 & 1,7 & 4 & 2,7 & 2,2 \\
\hline 6 & $\begin{array}{l}\text { PTertinggi } \\
\text { W) }\end{array}$ & 30,9 & 30,7 & 23,6 & 36,1 & 34,7 & 30,5 \\
\hline 7 & $\begin{array}{l}P_{\text {Rata- }} \\
\text { rata }(W)\end{array}$ & 15,4 & 14,2 & 10,7 & 19 & 15,4 & 14,2 \\
\hline
\end{tabular}

Rata-rata daya masak dan efisiensi kompor surya pada pengujian hari pertama yang tertinggi di dapat oleh kompor 4 dengan sudut $30^{\circ}$ dan penutup absorber kombinasi kaca fresnel. Hal ini karena semakin sempit ruang pemasakan kompor surya akan semakin kecil pula mengalami kehilangan panas atau losses. Besarnya daya masak dan efisiensi pada kompor 4 juga di pengaruhi oleh penutup absorber dengan menggunakan lensa fresnel yang langsung memfokuskan cahaya ke panci. Tabel 4. Memperlihatkan data pengujian hari ketiga kompor surya 4 tetap memiliki nilai suhu air dan efisiensi daya masak yang paling besar dibandingkan dengan yang lain. Pada pengujian hari ketiga didapatkan suhu kompor
4 sebesar $90^{\circ} \mathrm{C}$. Suhu pada kompor 4 di hari ketiga ini merupakan suhu yang paling tinggi dari hari sebelumnya, meskipun rata-rata nilai radiasi matahari di hari ketiga sebesar 883,8 tetapi tidak ada penurunan yang signifikan akan tetapi kecepatan angin pada hari ketiga rata-rata 2,3 lebih besar daripada hari pertama.

\section{Kesimpulan}

Berdasarkan hasil dari penelitian pada kompor surya tipe kotak dengan variasi sudut ruang masak dan penutup ruang masak dapat disimpulkan bahwa suhu air tertinggi dari pengujian selama 3 hari adalah $90^{\circ} \mathrm{C}$ pada variasi sudut ruang masak dengan kemiringan $30^{\circ} \mathrm{C}$ dengan penutup absorber kombinasi kaca fresnel di hari ketiga pada pukul 12.40 .

Berdasarkan data pengujian selama 3 hari dengan interval waktu 10 menit dengan durasi 240 menit didapatkan nilai rata-rata efisiensi dan daya masak tertinggi pada kompor 4 dengan kemiringan $30^{\circ}$ dengan penutup kaca dan fresnel sebesar $6,7 \%$ dengan daya masak 22,4 W pada pengujian hari pertama. Semakin besar sudut kompor surya maka semakin kecil atau sempit absorber yang didapatkan. Hal ini berpengaruh terhadap suhu air yang di uji karena apabila semakin sempit absorber maka kehilangan panas juga akan semakin kecil dan panas semakin memusat ke panci.

\section{Saran}

Diperlukan adanya penelitian lebih lanjut analisis optimasi penggunaan lensa Fresnel untuk meningkatkan suhu ruang pemasakan.

\section{Daftar Pustaka}

[1] G. Widayana, "Pemanfaatan Energi Surya," J. Pendidik. Teknol. Dan Kejuru., vol. 9, no. 1, 2012, doi: 10.23887/jptkundiksha.v9i1.2876.

[2] A. Muin, R. M. Veranika, dan I. Badil, "Perancangan Kompor Surya Serbaguna Dengan Susunan Absober Yang Bervariasi," J. DESIMINASI Teknol., vol. 5, no. 1, Jan 2017. 
[3] J. A. Duffie dan W. A. Beckman, "Solar Engineering of Thermal Processes," hlm. 928.

[4] A. K. Bnark dan N. Türkmen, "Modelling of a hot box solar cooker," Energy Convers. Manag., vol. 37, no. 3, hlm. 303310, Mar 1996, doi: 10.1016/01968904(95)00183-2.

[5] R. E. Rachmanita dan H. Ahmadi, "Aplikasi Interdigital Capacitor Sensor (IDCS) dalam pengukuran permitivitas relatif Crude Oil," J. Pendidik. Fis. Dan Keilmuan JPFK, vol. 5, no. 2, Sep 2019, doi: $10.25273 /$ jpfk.v5i2.4011.

[6] Asrori $d k k$., "Konsentrator Lensa Fresnel : Kajian Pemanfaatan Energi Panas Matahari Untuk Aplikasi Kompor Surya," 2014, doi: 10.13140/RG.2.1.2015.8885.

[7] R. E. Rachmanita dan H. Ahmadi, "Perancangan Perancangan Sistem Pengukuran Kapasitansi Crude Oil Menggunakan Interdigital Capasitors (IDCs) Berbasis Arduino Uno," JIPFRI J. Inov. Pendidik.Fis. Dan Ris. Ilm., vol. 3, no. 2, hlm. 54-61, Nov 2019, doi: 10.30599/jipfri.v3i2.471.
[8] H. Wang, J. Huang, M. Song, dan J. Yan, "Effects of receiver parameters on the optical performance of a fixed-focus Fresnel lens solar concentrator/cavity receiver system in solar cooker," Appl. Energy, vol. 237, hlm. 70-82, Mar 2019, doi: 10.1016/j.apenergy.2018.12.092.

[9] R. E. Rachmanita, "The High Capacitance for Electrode Structure of Interdigital Capacitor Thin Film Models," SNRU J. Sci. Technol., vol. 11, no. 2, hlm. 55-63, Apr 2019.

[10] F. Wijayanti dan H. Ahsan, "Uji Kinerja Kompor Surya Dengan Variasi Bentuk Geometri Dan Luas Kolektor," hlm.7, 2012.

[11] F. Burlian dkk., "Rancang Bangun Kompor Energi Surya Tipe Kotak Dengan Sistem Konsentator Cermin Datar Di Kelompok Pengusaha Kecil Pembuat Tempe Di Lemabang Palembang," 23-Okt2011. [Daring]. Tersedia pada: http://repository.unsri.ac.id/21436/.

[Diakses: 20-Feb-2020].

[12] P. R. Bailis, D. Ogle, N. MacCarty, K. R. Smith, dan R. Edwards, "The Water Boiling Test (WBT)," hlm. 38, 2007. 
